\title{
Dynamic Cure Kinetics and Physical-Mechanical Properties of PEG/Nanosilica/Epoxy Composites
}

\author{
Haleh Nowruzi Varzeghani, Iraj Amiri Amraei $(\mathbb{D}$, and Seyed Rasoul Mousavi \\ Department of Material Science and Manufacturing Technology, Malek Ashtar University of Technology, Tehran 158751774, Iran \\ Correspondence should be addressed to Iraj Amiri Amraei; iraj_amiri@yahoo.com
}

Received 22 December 2019; Accepted 11 February 2020; Published 26 February 2020

Academic Editor: Jan-Chan Huang

Copyright (c) 2020 Haleh Nowruzi Varzeghani et al. This is an open access article distributed under the Creative Commons Attribution License, which permits unrestricted use, distribution, and reproduction in any medium, provided the original work is properly cited.

\begin{abstract}
This study investigated the effect of polyethylene glycol (PEG) and nanosilica (NS) on the physical-mechanical properties and cure kinetics of diglycidyl ether of bisphenol-A-based epoxy (DGEBA-based EP) resin. For this purpose, tensile and viscometry tests, dynamic mechanical thermal analysis (DMTA), and differential scanning calorimetry (DSC) were carried out under dynamic conditions. The results showed that adding NS and PEG enhances the maximum cure temperature as well as the heat of cure reaction $(\Delta H)$ in EP-NS, while it decreases in EP-PEG and EP-PEG-NS. The cure kinetic parameters of EP-PEG-NS were calculated by Kissinger, Ozawa, and KSA methods and compared with each other. The $E_{a}$ calculated from the Kissinger method $(96.82 \mathrm{~kJ} / \mathrm{mol})$ was found to be lower than that of the Ozawa method $(98.69 \mathrm{~kJ} / \mathrm{mol})$. Also, according to the KAS method, the apparent $E_{a}$ was approximately constant within the 10-90\% conversion range. Tensile strength and modulus increased by adding NS, while tensile strength diminished slightly by adding PEG to EP-NS. The glass transition temperature $\left(T_{\mathrm{g}}\right)$ was calculated using DMTA which was increased and decreased by the addition of NS and PEG, respectively. The results of the viscometry test showed that the viscosity increased with the presence of both PEG and NS and it prevented the deposition of solid particles.
\end{abstract}

\section{Introduction}

Because of their excellent thermal and mechanical properties, epoxy (EP) resins are widely used in structural adhesives [1], insulating materials [2], resin matrices for high performance composites [3], protective coatings [4], electronic and electronical components $[5,6]$, etc. These wide applications are due to creep resistance [7], excellent adhesion to many substrates [8], high temperature performance [9], high stiffness [10], and high mechanical and electrical properties [11]. However, almost all EPs are brittle [12-14]. Many tougheners such as carboxyl-terminated butadiene-acrylonitrile (CTBN) $[15,16]$, core-shell rubber (CSR) particles [17, 18], thermoplastic or thermoset polymers [19,20], and organicinorganic particles [21, 22] have been incorporated to increase the toughness of EP resins. These tougheners decrease modulus, tensile strength, and glass transition temperature $\left(T_{\mathrm{g}}\right)$; so in order to enhance the mechanical and thermal properties, the toughened EPs are reinforced by nanosilica (NS) particles. Mousavi and Amraei [23] used EP-CSR-NS composites and found that NS partially offsets the reduction in properties caused by CSR.

The properties of cured EPs depend on curing conditions such as time and temperature. Differential scanning calorimetry (DSC) has been used to investigate the kinetics of cure process under dynamic $[24,25]$ and isothermal $[26,27]$ modes. Many kinetic models have been used to study kinetic parameters, such as Kissinger [28, 29], Ozawa [30, 31], Kissinger-Akahira-Sunose (KSA) [32, 33], Flynn-WallOzawa (FWO) [28, 34], Kamal [35, 36], autocatalytic $[37,38]$, and Borchardt Daniels $[39,40]$ methods.

Many researchers [41] have observed that the main problem with thermoplastics tougheners is compatibility with the EP resin. Because of aromatic rings in DGEBA EP resin, it has high mechanical properties after curing, and it is miscible with polyethylene glycol (PEG) $[42,43]$. Thus, this grade of EP resin was blended with PEG and NS in this study. Further, the physical-mechanical, viscometry, and thermal properties 
<smiles>CC(C)(c1ccc(OCC(O)COc2ccc(C(C)(C)c3ccc(OCC4CO4)cc3)cc2)cc1)c1ccc(OCC2CO2)cc1</smiles>

EP<smiles>N#CNC(=N)N</smiles>

DICY<smiles>CN(C)C(=O)Nc1ccc(Cl)c(Cl)c1</smiles>

Diuron<smiles>COCCC(C)C</smiles>

PEG<smiles>C[Si](C)([O-])[O-]</smiles>

NS

Figure 1: Chemical structures of the EP, DICY, Diuron, PEG, and NS.

TAble 1: The chemical and physical properties of the EP, DICY, Diuron, PEG, and NS.

\begin{tabular}{|c|c|c|}
\hline Material & Property & \\
\hline \multirow{3}{*}{ EP (DGEBA) } & EEW (g/eq) & $185-192$ \\
\hline & Viscosity at $25^{\circ} \mathrm{C}(\mathrm{P})$ & $110-150$ \\
\hline & Density at $25^{\circ} \mathrm{C}\left(\mathrm{g} / \mathrm{cm}^{3}\right)$ & 0.97 \\
\hline \multirow{4}{*}{ DICY } & Molecular weight (g/mol) & 84.08 \\
\hline & Melting point $\left({ }^{\circ} \mathrm{C}\right)$ & $208-210$ \\
\hline & Solubility in water $\left(\mathrm{g} / 100 \mathrm{~g} \mathrm{H}_{2} \mathrm{O}\right)$ & 3.2 \\
\hline & Solubility in epoxy at $25^{\circ} \mathrm{C}\left(\mathrm{g} / 100 \mathrm{~g}\right.$ epoxy $\left.{ }^{\mathrm{a}}\right)$ & 0.05 \\
\hline \multirow{3}{*}{ Diuron } & Molecular weight (g/mol) & 233.09 \\
\hline & Melting point $\left({ }^{\circ} \mathrm{C}\right)$ & 159 \\
\hline & Solubility in water $\left(\mathrm{g} / 100 \mathrm{~g} \mathrm{H}_{2} \mathrm{O}\right)$ & 0.0042 \\
\hline \multirow{3}{*}{ PEG } & Molecular weight (g/mol) & 4000 \\
\hline & Viscosity at $100^{\circ} \mathrm{C}(\mathrm{cSt})$ & 140.4 \\
\hline & Density $\left(\mathrm{g} / \mathrm{cm}^{3}\right)$ & 1.0926 \\
\hline \multirow{2}{*}{ NS } & Average particle size (nm) & 16 \\
\hline & Tapped density (g/L) & 50 \\
\hline
\end{tabular}

DGEBA: diglycidyl ether of bisphenol-A; EEW: epoxy equivalent weight. ${ }^{a} E p o x y$ resin Epon 828, based on the DGEBA.

were investigated. Finally, the cure kinetics of EP-PEG-NS composites were studied using Kissinger, Ozawa, and KSA methods.

\section{Materials and Methods}

2.1. Materials. DGEBA EP resin (Epon 828) was supplied from Shell with an epoxide equivalent weight of 185$192 \mathrm{~g} / \mathrm{eq}$. The DICY as a curing agent and Diuron as an accelerator were obtained from Sigma-Aldrich. PEG used was supplied by Merck with an average molecular weight of $4000 \mathrm{~g} / \mathrm{mol}$. NS (Aerosil R972) was prepared from Evonik. All of the materials were used as received. The chemical structures of the materials used in this study are shown in Figure 1. The chemical and physical properties also are reported in Table 1.

2.2. Sample Preparation. Initially, EP, DICY, and NS were homogeneously mixed by a Perl Mill. Then, they were blended with Diuron and PEG using a High-Shear mixer (IKA T25). Next, the mixture of resin and other materials was degassed in a vacuum oven at $50^{\circ} \mathrm{C}$ for $30 \mathrm{~min}$. Afterwards, the samples were gently poured into mold and cured at $120^{\circ} \mathrm{C}$ for $90 \mathrm{~min}$. The details of experimental setup were according to Mousavi and Amraei previous work (Figure 2) [23]. Details of the composition of the formulations are listed in Table 2.

2.3. Mechanical Properties. A Santam STM-150 tensile/compression testing machine was employed to the investigate mechanical properties of dumbbell shaped specimens at a crosshead speed of $5 \mathrm{~mm} / \mathrm{min}$ according to ASTM D-638 (I-type).

2.4. Dynamic Mechanical Thermal Analysis. Dynamic mechanical thermal analysis (DMTA) was conducted using a TA Instruments DMTA 2980 analyzer. Rectangular specimens with dimensions of $2 \times 3 \times 48 \mathrm{~mm}^{3}$ were used. 


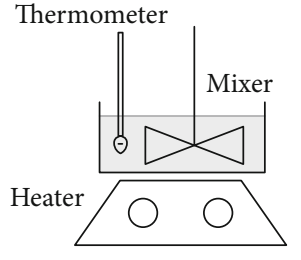

(1)

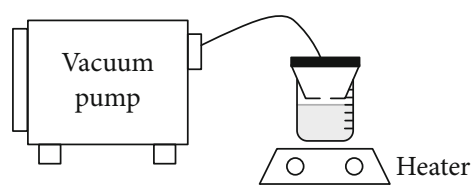

(2)

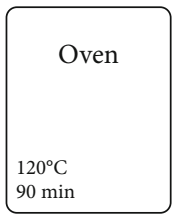

(3)

Figure 2: Details of the experimental setup.

TABLE 2: Details of composition of the formulations.

\begin{tabular}{lcccc}
\hline Sample & DICY (phr) & Diuron (phr) & PEG (phr) & NS (phr) \\
\hline EP & 7 & 3 & 0 & 0 \\
EP-PEG & 7 & 3 & 10 & 0 \\
EP-NS & 7 & 3 & 0 & 3 \\
EP-PEG-NS & 7 & 3 & 10 & 3 \\
\hline
\end{tabular}

phr: parts per hundred parts of resin by weight.

Temperature sweeps were performed at a rate of $5^{\circ} \mathrm{C} / \mathrm{min}$ and a frequency of $1 \mathrm{~Hz}$, from 25 to $200^{\circ} \mathrm{C}$.

2.5. Viscosity Test. Viscosity measurement was performed using a Brookfield viscometer ranging from room temperature up to $65^{\circ} \mathrm{C}$ according to ASTM D2196.

2.6. Kinetic Models. The curing kinetics of the samples was examined on a differential scanning calorimeter (DSC, Netzsch DSC 200F3) under nitrogen atmosphere. Dynamic measurements were carried out from 25 to $250^{\circ} \mathrm{C}$ at heating rates of $2.5,5$, and $10^{\circ} \mathrm{C} / \mathrm{min}$.

In the DSC analysis, we can assume that the area under the exothermic curve is proportional to the degree of conversion $(\alpha)$, which is expressed as follows $[44,45]$ :

$$
\alpha=\frac{H_{t}}{\Delta H},
$$

where $H_{t}$ is the partial heat of cure reaction at time $t$ and $\Delta H$ is the total heat of cure reaction. Curing kinetics of EP is a very complex process, and there are a variety of physicochemical reaction, and the activation energy $\left(E_{a}\right)$ changes at any point in time. Accordingly, in this study, the $E_{a}$ has been calculated by different dynamic methods. These methods are described as follows:

\subsubsection{Kissinger Method.}

$$
\ln \frac{\beta}{T_{\mathrm{p}}^{2}}=\ln \left(\frac{A R}{E_{a}}\right)-\frac{E_{a}}{R T_{\mathrm{p}}}
$$

where $\beta$ represents the heating rate, $T_{\mathrm{p}}$ is the absolute temperature at the peak, $A$ denotes the preexponential factor, and $R$ is the gas constant. If the curve of $\ln \left(\beta / T_{\mathrm{p}}^{2}\right)$ versus $1 / T_{\mathrm{p}}$ is plotted for different heating rates and linear extrapolation is obtained, the slope of that line gives the value of $E_{a}$.
TABLE 3: Mechanical properties of different samples.

\begin{tabular}{lccc}
\hline Sample & $\begin{array}{c}\text { UTS } \\
(\mathrm{MPa})\end{array}$ & $\begin{array}{c}\text { Young's modulus } \\
(\mathrm{GPa})\end{array}$ & $\begin{array}{c}\text { Strain at break } \\
(\%)\end{array}$ \\
\hline EP & $73 \pm 3$ & $2.9 \pm 0.05$ & $3.1 \pm 0.02$ \\
EP-MEG & $69 \pm 1$ & $2.96 \pm 0.1$ & $3.24 \pm 0.05$ \\
EP-NS & $83 \pm 2$ & $3.17 \pm 0.2$ & $4.1 \pm 0.3$ \\
EP-PEG-NS & $75 \pm 2$ & $3.22 \pm 0.05$ & $3.52 \pm 0.2$ \\
\hline
\end{tabular}

2.6.2. Ozawa Method.

$$
\frac{d(\ln \beta)}{d\left(1 / T_{\mathrm{p}}\right)}=1.052\left(\frac{E_{a}}{R}\right)
$$

where all of parameters are the same as described before. If the curve of $\ln \beta$ versus $1 / T_{\mathrm{p}}$ is plotted for different heating rates and linear extrapolation is obtained, the slope of that line gives the quantity of $E_{a}$.

\subsubsection{Kissinger-Akahira-Sunose (KAS) Method.}

$$
\ln \left(\frac{\beta}{T_{\alpha}^{2}}\right)=C-\frac{E_{a}}{R T_{\alpha}},
$$

where $T_{\alpha}$ is the absolute temperature at a fixed $\alpha$ and $C$ is a constant. If the curve of $\ln \left(\beta / T_{\alpha}^{2}\right)$ versus $1 / T_{\alpha}$ is plotted for different heating rates and linear extrapolation is obtained, the slope of that line gives the value of $E_{a}$.

\section{Results and Discussion}

3.1. Mechanical Properties. Table 3 presents the ultimate tensile strength (UTS), Young's modulus, and strain at break. It was observed by adding NS, UTS, and Young's modulus of the EP increased without any reduction in strain at break. It is because as the tensile force is applied to the specimens, the silica nanoparticles lead to increased deformation resistance. On the other hand, the deformation decreases in EP-PEG-NS due to the presence of flexible chains in PEG. As such, the tensile strength declines slightly with respect to EP-NS. Cured EP resin has high internal stresses due to the shrinkage resulting from the cooling from curing temperature to room temperature. These internal stresses affect the performance through producing cavities and microcracks. 


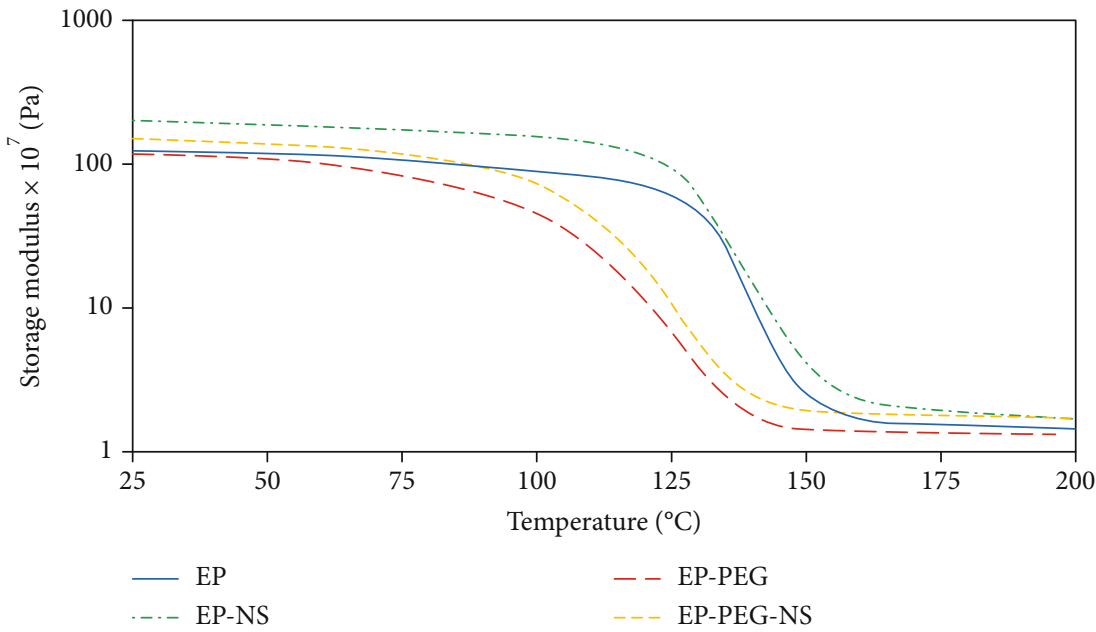

(a)

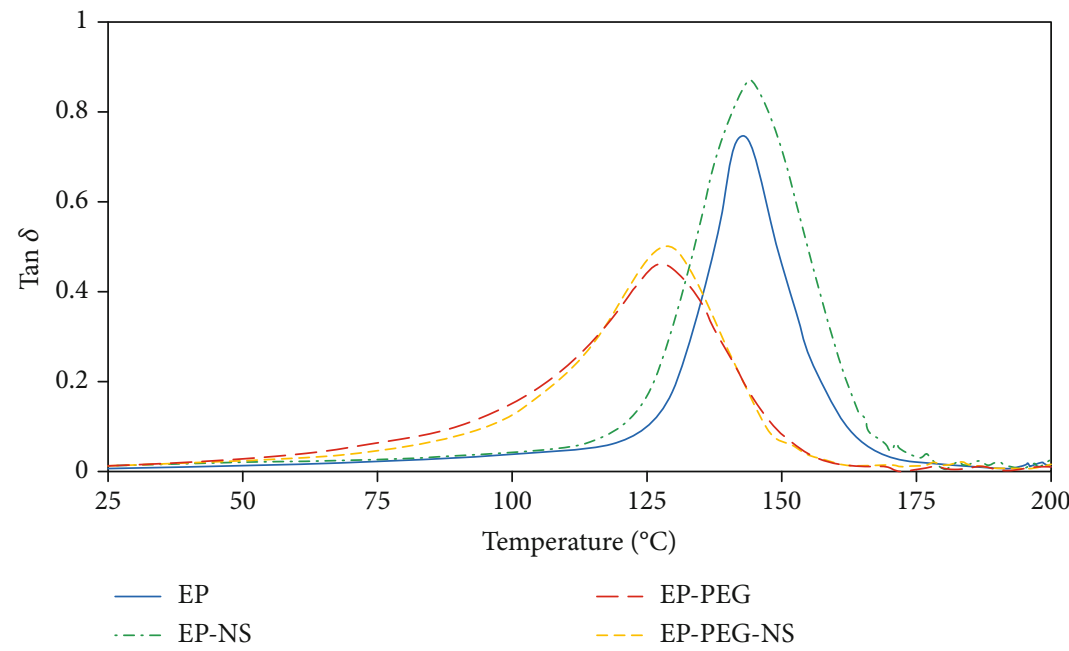

(b)

Figure 3: (a) Storage modulus and (b) $\tan \delta$ versus temperature.

TABLE 4: Glass transition temperature for all samples.

\begin{tabular}{lc}
\hline Sample & $T_{\mathrm{g}}\left({ }^{\circ} \mathrm{C}\right)$ \\
\hline EP & 129.5 \\
EP-PEG & 103.2 \\
EP-NS & 124.7 \\
EP-PEG-NS & 105.2 \\
\hline
\end{tabular}

Induction of PEG soft segments to EP dramatically reduces these internal stresses.

3.2. Dynamic Mechanical Thermal Analysis. Figure 3(a) indicates storage modulus $\left(E^{\prime}\right)$ versus temperature. A temperature at which the maximum value of $\tan \delta$ occurs is the glass transition temperature. $T_{\mathrm{g}}$ of all the samples is shown in Table 4. Adding PEG reduces the modulus and $T_{\mathrm{g}}$. One of the reasons for the fall in $T_{\mathrm{g}}$ is the low $T_{\mathrm{g}}$ of PEG $\left(-23^{\circ} \mathrm{C}\right)$. The reduction in $T_{\mathrm{g}}$ is also attributed to a decrease
TABle 5: The tan $\delta$ curve peak of the samples.

\begin{tabular}{lcc}
\hline Sample & Temperature at peak $\left({ }^{\circ} \mathrm{C}\right)$ & $\tan \delta$ at peak \\
\hline EP & 142.7 & 0.7467 \\
EP-PEG & 128.5 & 0.4621 \\
EP-NS & 143.9 & 0.8721 \\
EP-PEG-NS & 128.8 & 0.5004 \\
\hline
\end{tabular}

TABLe 6: The effect of temperature elevation on the viscosity of samples.

\begin{tabular}{lcccc}
\hline \multirow{2}{*}{ Sample } & \multicolumn{4}{c}{ Viscosity (cp) at } \\
& $25^{\circ} \mathrm{C}$ & $50^{\circ} \mathrm{C}$ & $60^{\circ} \mathrm{C}$ & $65^{\circ} \mathrm{C}$ \\
\hline EP & 26800 & 1940 & 574 & 450 \\
EP-PEG & 36522 & 1696 & 615 & 530 \\
EP-NS & 73400 & 1280 & 530 & 370 \\
EP-PEG-NS & 76350 & 7680 & 3600 & 2915 \\
\hline
\end{tabular}




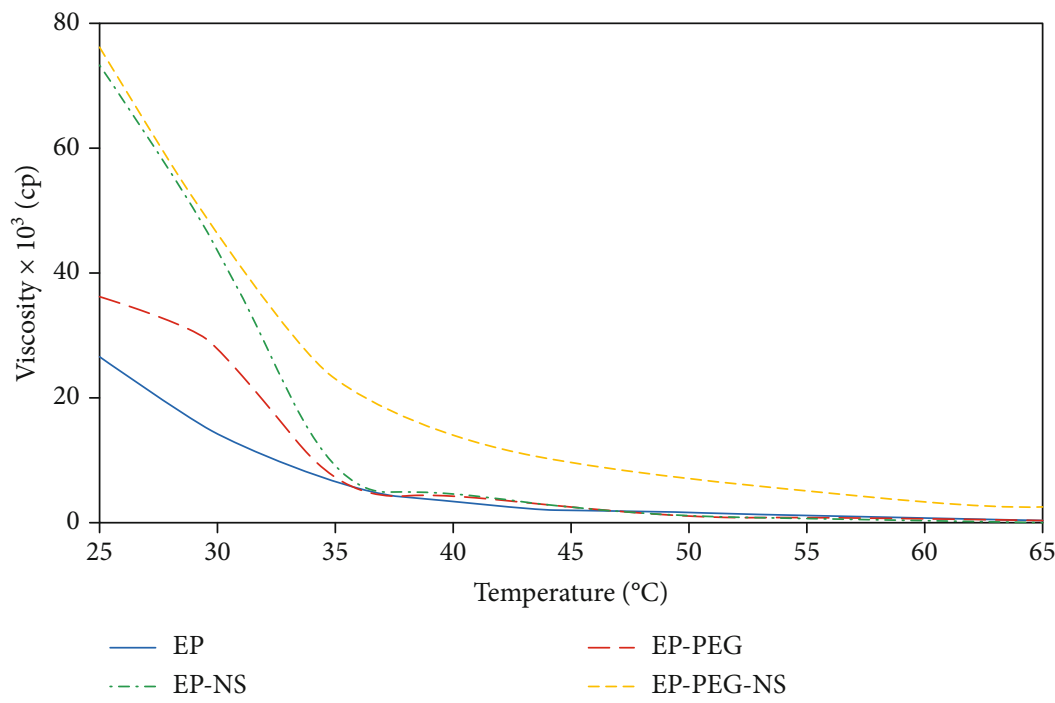

FIGURE 4: Viscosity-temperature diagrams of different samples.

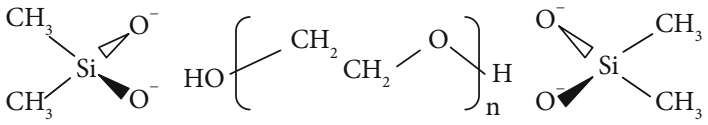

FIGURE 5: Reaction between PEG and NS.

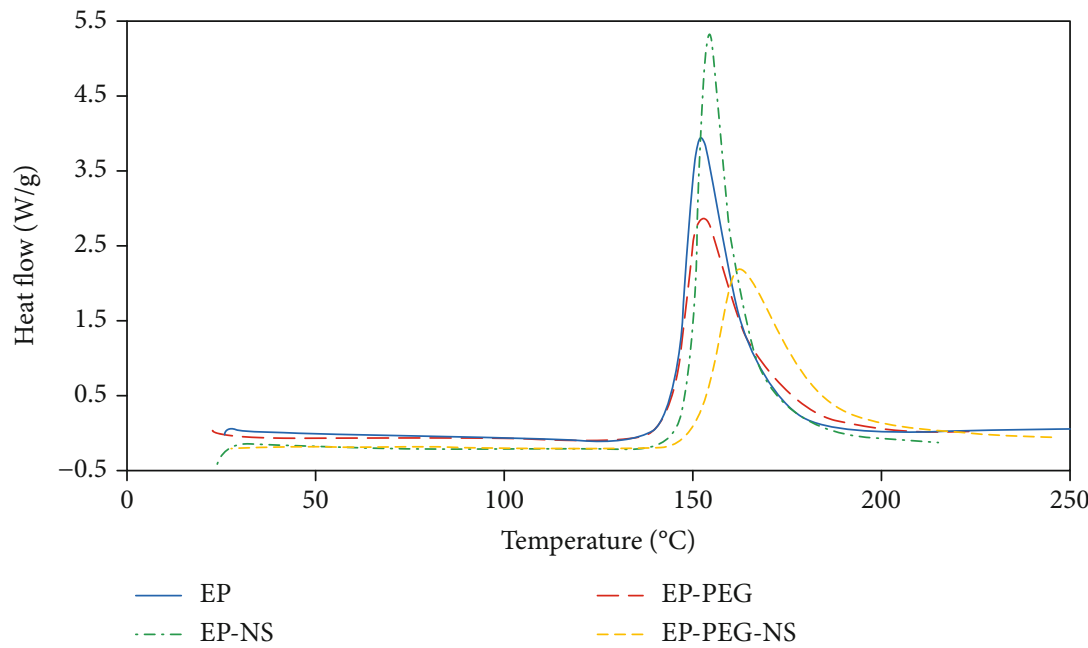

FIGURE 6: Heating flow versus temperature for all samples.

in the rigidity of the polymer chains and a drop in the density of crosslinks due to the presence of flexible PEG chains. The highest $E^{\prime}$ belonged to EP-NS, EP-PEG-NS, and EP-PEG, respectively. As can be seen, the presence of flexible chains in PEG has strongly affected the modulus of samples and the mobility of chains.

Figure 3(b) shows variations of $\tan \delta$ versus temperature. The $\tan \delta$ indicates which sample is better at absorbing energy. The highest $\tan \delta$ curve peak was observed in EPNS. This suggests that this sample has the maximum extent
TABLE 7: The results of the DSC test of the samples at the heating rate of $10^{\circ} \mathrm{C} / \mathrm{min}$.

\begin{tabular}{lcc}
\hline Sample & $T_{\text {peak }}\left({ }^{\circ} \mathrm{C}\right)$ & $\Delta H(\mathrm{~J} / \mathrm{g})$ \\
\hline EP & 151.3 & 382.1 \\
EP-PEG & 152 & 341 \\
EP-NS & 153.5 & 414.7 \\
EP-PEG-NS & 162 & 366.3 \\
\hline
\end{tabular}




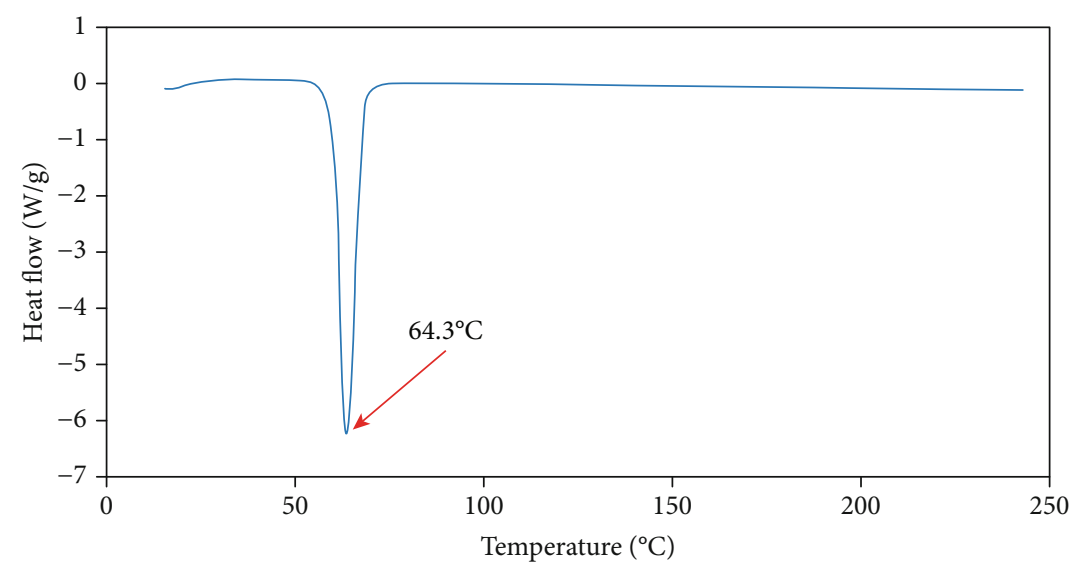

FIGURE 7: Heating flow rates versus temperature for PEG.

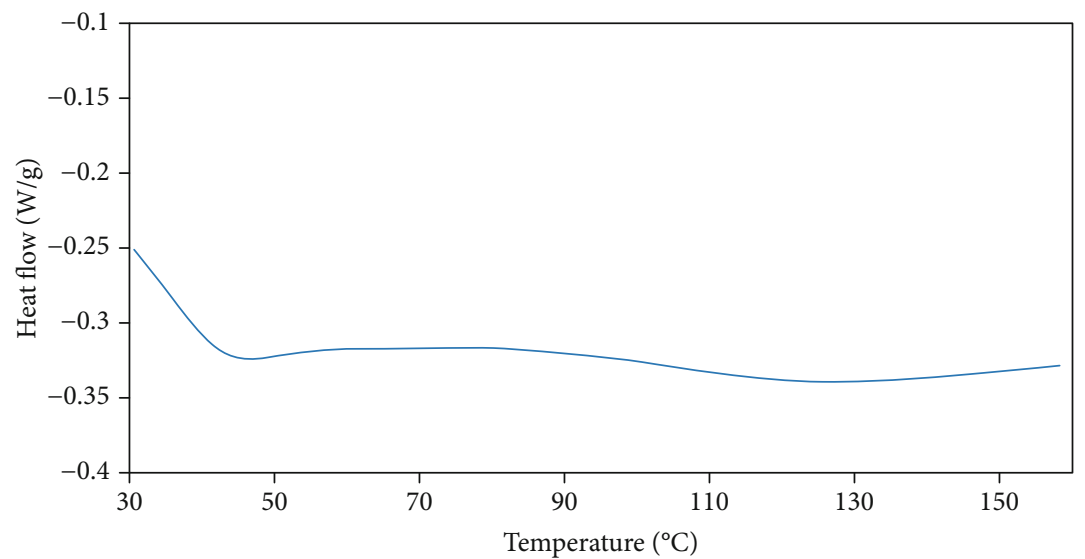

FIGURE 8: Heating flow rates versus temperature for cured EP-PEG-NS.

of energy loss. Table 5 reports the $\tan \delta$ curve peak of the samples. Adding NS transfers $\tan \delta$ curve peak to higher temperatures while adding PEG transfers $\tan \delta$ curve peak to lower temperatures. The wider the area under the $\tan \delta$ curve, the greater toughness is. The EP-PEG has a wider area under curve compared EP-NS. This indicates that EP-PEG has greater fracture energy than EP-NS.

3.3. Viscometry Test. Table 6 shows the effect of temperature rise on the viscosity of samples. Viscosity-temperature diagrams are also displayed in Figure 4. EP-PEG-NS had a higher viscosity over the entire range of 25 to $65^{\circ} \mathrm{C}$ compared to the other samples. This indicates that the viscosity increased with the presence of both PEG and NS and it prevented the deposition of solid particles. This is attributed to the melting temperature of PEG $\left(50-58^{\circ} \mathrm{C}\right)$. At this temperature, PEG has a viscosity of $70-80 \mathrm{cp}$. After the melting of $\mathrm{PEG}, \mathrm{OH}$ groups of the $\mathrm{PEG}$ react with $\mathrm{O}$ groups of the NS (Figure 5), and by forming active groups on the surface of NS, it results in the formation of agglomerations thereby enhancing viscosity.

3.4. DSC Analysis. Figure 6 depicts the heating flow rates versus temperature for all samples at heating rates of $10^{\circ} \mathrm{C} / \mathrm{min}$.
The results of the DSC test are presented in Table 7. As can be seen, adding NS and PEG raises the maximum cure temperature. The heat of cure reaction (the area under the exothermic peak, $\Delta H$ ) increases in EP-NS and diminishes in EP-PEG and EP-PEG-NS (more reduction in EP-PEG).

Figure 7 displays the DSC scan of PEG. As can be seen, within the temperature range of 60 to $70^{\circ} \mathrm{C}$, it indicates a melting peak. The DSC scan of the cured EP-PEG-NS is also shown in Figure 8 which is used to check for complete curing of the sample. As it is seen, there is no melting peak suggesting the complete curing of the EP-PEG-NS. The $T_{\mathrm{g}}$ obtained from DSC is about $86.6^{\circ} \mathrm{C}$, which differs by about $18^{\circ} \mathrm{C}$ from the $T_{\mathrm{g}}$ obtained from DMTA.

3.5. Investigating of Curing Kinetics of EP-MEG-NS. In order to investigate the dynamic cure kinetics of the EP-PEG-NS, first, the DSC test was performed on the uncured sample at heating rates of $2.5,5$, and $10^{\circ} \mathrm{C} / \mathrm{min}$. Figure 9 presents the heating flow rates versus temperature and time for uncured EP-PEG-NS. As expected, as the heating rate increased, the exothermic peak shifted to higher temperatures.

The degree of conversion $(\alpha)$ versus temperature and cure rate $(d \alpha / d t)$ versus the degree of conversion at heating 


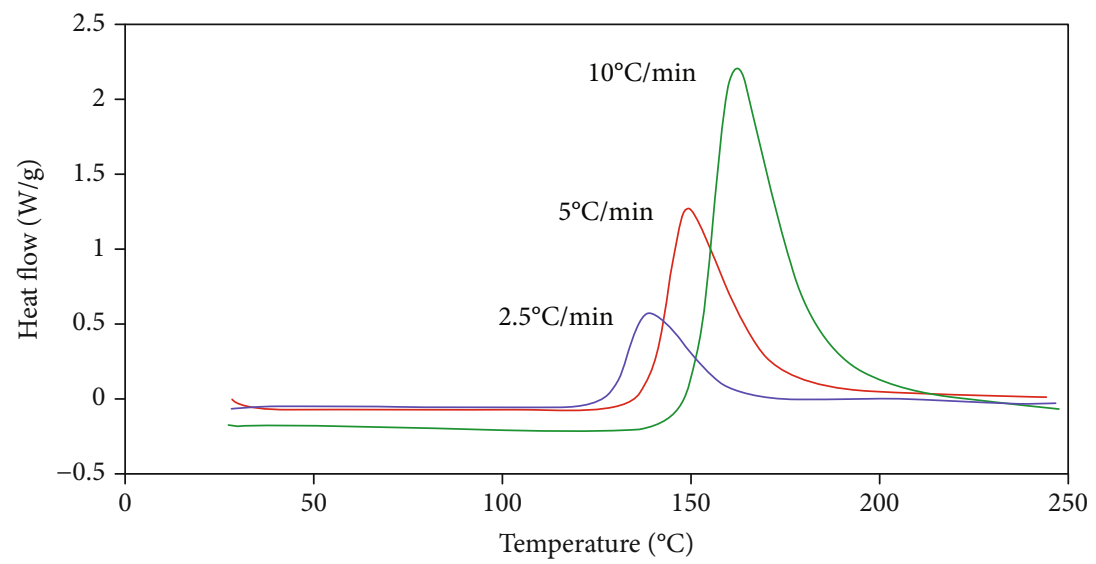

(a)

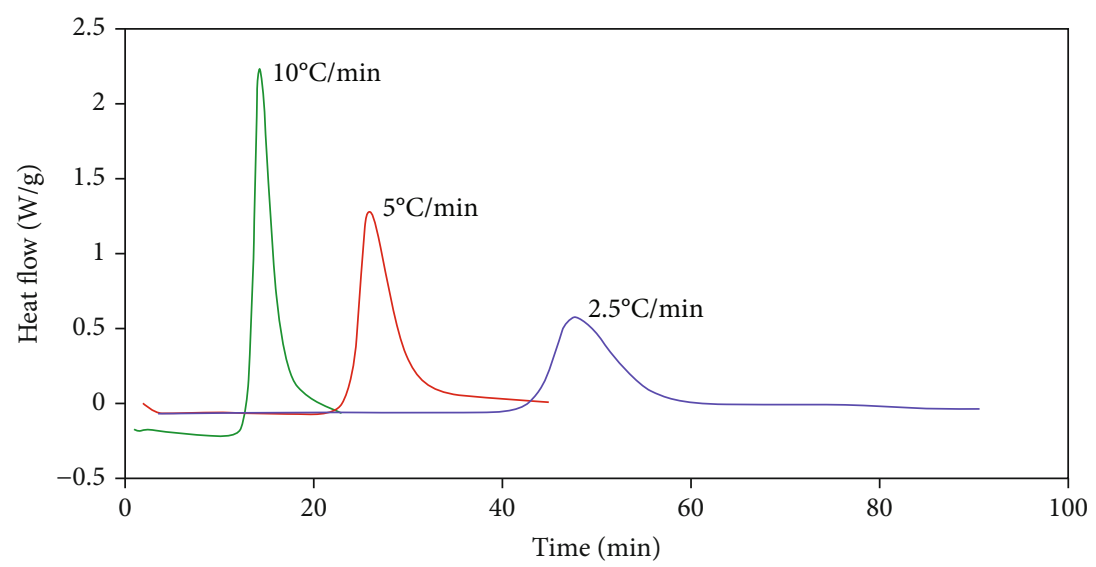

(b)

FIgURE 9: The heating flow rates versus (a) temperature and (b) time for uncured EP-PEG-NS.

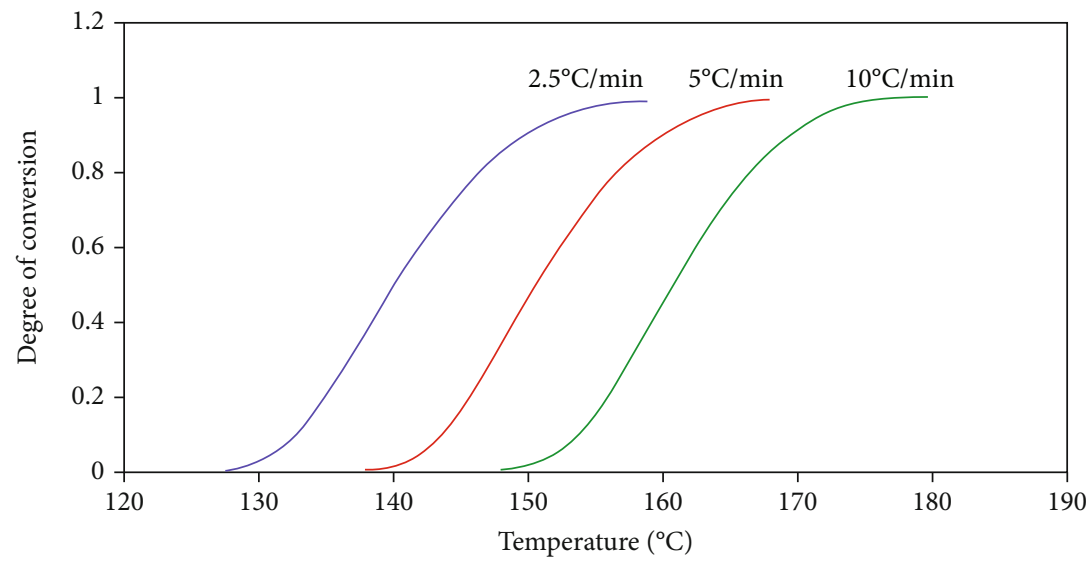

FIgURE 10: The degree of conversion versus temperature for uncured EP-PEG-NS.

rates of $2.5,5$, and $10^{\circ} \mathrm{C} / \mathrm{min}$ is shown in Figures 10 and 11 , respectively. As can be seen in Figures 9 and 11, the curing process has occurred under two reactions: kinetic control and penetration control. First, the curing process is the kinetic control, and the graph reaches the peak at a considerable speed. The reason is that as the reaction progresses, more crosslinks are formed between the polymer chains and its movement has become more difficult. Hence, the contribution of the penetration control is more than that of the kinetic control at higher curing degrees.

The variations of $E_{a}$ at different $\alpha$ values were also calculated using KAS equation (equation (4)). Table 8 shows $E_{a}$ at 


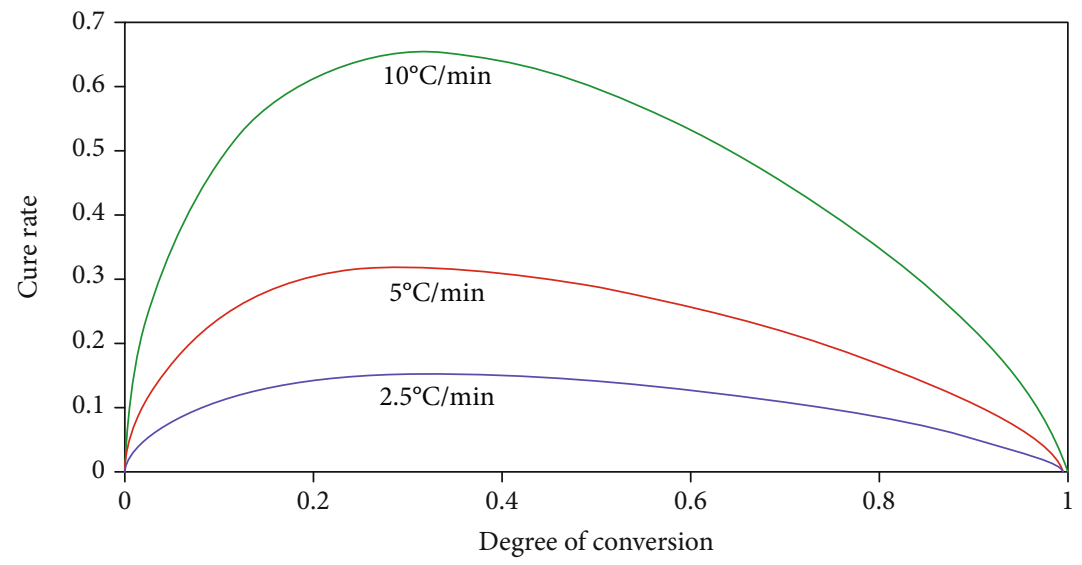

FIGURE 11: The cure rate versus degree of conversion for uncured EP-PEG-NS.

TABLe 8: $E_{a}$ at different conversions of EP-PEG-NS.

\begin{tabular}{|c|c|c|c|c|c|c|c|c|c|c|}
\hline & \multicolumn{10}{|c|}{ Conversion } \\
\hline & $10 \%$ & $20 \%$ & $30 \%$ & $40 \%$ & $50 \%$ & $60 \%$ & $70 \%$ & $80 \%$ & $90 \%$ & Average \\
\hline$\overline{E_{a}(\mathrm{~kJ} / \mathrm{mol})}$ & 92.53 & 89.38 & 87.45 & 90.81 & 93.98 & 94.85 & 97.18 & 102.47 & 98.65 & 94.14 \\
\hline
\end{tabular}

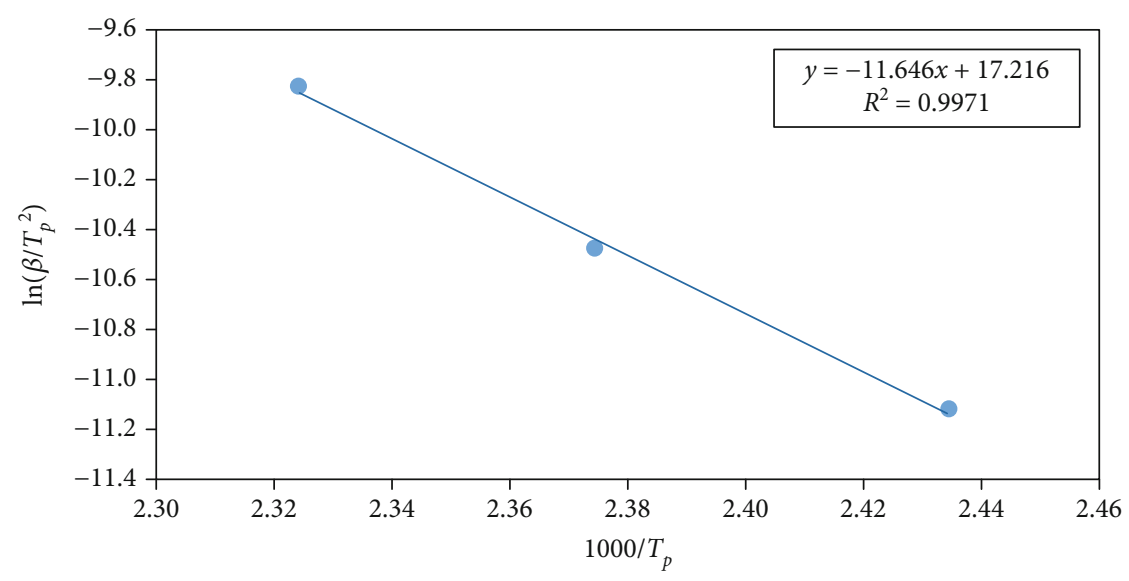

(a)

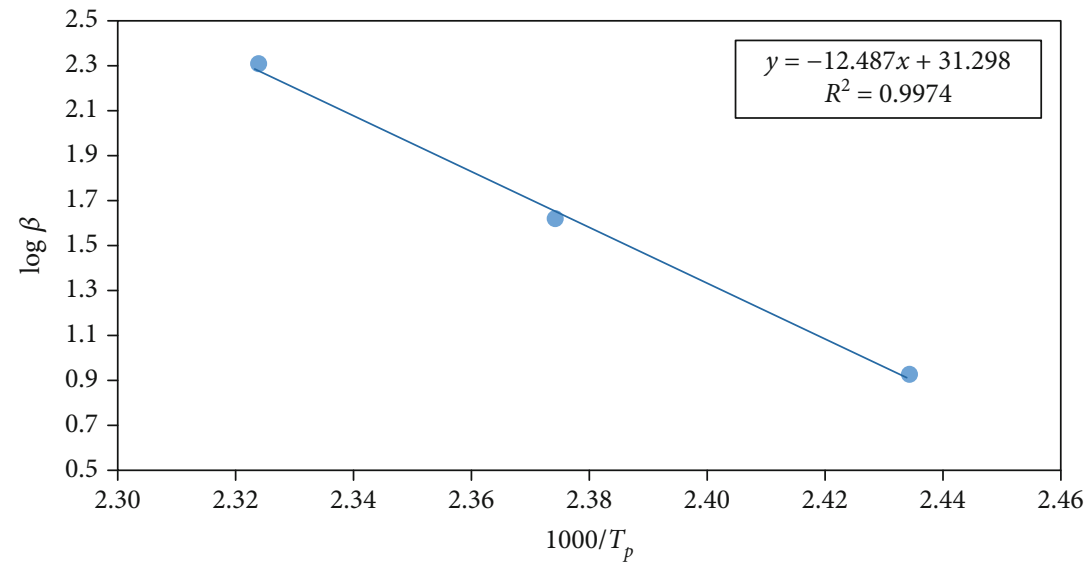

(b)

FIGURE 12: The plots obtained using (a) Kissinger and (b) Ozawa methods. 
different conversions of EP-PEG-NS. As can be seen, the apparent $E_{a}$ was approximately constant within the $10-90 \%$ conversion range.

$E_{a}$ of the curing reaction was calculated using Kissinger and Ozawa methods with the peak temperature determined from DSC curves. In the Kissinger method, $E_{a}$ was found to be $96.82 \mathrm{~kJ} / \mathrm{mol}$. $E_{a}$ calculated from the Ozawa method $(98.69 \mathrm{~kJ} / \mathrm{mol})$ was found to be higher than that of the Kissinger method. Singh et al. [45] also reported similar results for EP-based composites. Figure 12 indicates the plots obtained using Kissinger and Ozawa methods.

\section{Conclusions}

In the present paper, physical-mechanical and cure kinetics of blends of EP/DICY with PEG and NS were studied through tensile and viscometry test, DMTA, and DSC. By adding NS and PEG, the maximum cure temperature as well as the heat of cure reaction $(\Delta H)$ increased in EP-NS, while it diminished in EP-PEG and EP-PEG-NS. $E_{a}$ calculated from the Kissinger method $(96.82 \mathrm{~kJ} / \mathrm{mol})$ was found to be less than that of the Ozawa method $(98.69 \mathrm{~kJ} / \mathrm{mol})$. Also, according to the KAS method, the apparent $E_{a}$ was approximately constant within the $10-90 \%$ conversion range. The results of mechanical tests revealed that tensile strength and modulus increased by adding NS, while the tensile strength dropped slightly by adding PEG to EP-NS. The glass transition temperature $\left(T_{\mathrm{g}}\right)$ was calculated using DMTA; according to the results, NS and PEG led to heightened and diminished $T_{\mathrm{g}}$, respectively. Also, the viscosity increased with the presence of both PEG and NS, and it prevented the deposition of solid particles.

\section{Data Availability}

The data used to support the findings of this study are currently under embargo while the research findings are commercialized. Requests for data, 12 months after publication of this article, will be considered by the corresponding author.

\section{Conflicts of Interest}

The authors declare that they have no conflicts of interest.

\section{References}

[1] G. Hu, X. Zhang, L. Liu, and L. Weng, "Improvement of graphene oxide/epoxy resin adhesive properties through interface modification," High Performance Polymers, vol. 31, no. 3, pp. 341-349, 2018.

[2] V. Shahedifar, A. Masoud Rezadoust, and I. Amiri Amraei, "Comparison of physical, thermal, and thermomechanical properties of cotton/epoxy composite and cotton/vinyl ester composite inhibitors," Propellants, Explosives, Pyrotechnics, vol. 41, no. 2, pp. 321-326, 2016.

[3] C. Chen, Y. Tang, Y. S. Ye et al., "High-performance epoxy/silica coated silver nanowire composites as underfill material for electronic packaging," Composites Science and Technology, vol. 105, pp. 80-85, 2014.
[4] X. Yan, Y. Cai, R. Lu, and T. Miyakoshi, "Development and Characterization of New Coating Material of Blended EpoxyLacquer with Aluminum," International Journal of Polymer Science, vol. 2017, 8 pages, 2017.

[5] Z. Wang, W. Zhou, X. Sui et al., "Dielectric studies of al nanoparticle reinforced epoxy resin composites," Polymer Composites, vol. 39, no. 3, pp. 887-894, 2018.

[6] Y. Liu, X. Yang, L. Yue, W. Li, W. Gan, and K. Chen, "Selective dispersion of silver nanowires in epoxy/polyetherimide binary composites with enhanced electrical conductivity: a study of curing kinetics and morphology," Polymer Composites, vol. 40, no. 11, pp. 4390-4401.

[7] O. Starkova, S. T. Buschhorn, E. Mannov, K. Schulte, and A. Aniskevich, "Creep and recovery of epoxy/MWCNT nanocomposites," Composites Part A: Applied Science and Manufacturing, vol. 43, no. 8, pp. 1212-1218, 2012.

[8] Y.-H. Ji, Y. Liu, G. W. Huang, X. J. Shen, H. M. Xiao, and S. Y. $\mathrm{Fu}$, "Ternary Ag/epoxy adhesive with excellent overall performance," ACS Applied Materials \& Interfaces, vol. 7, no. 15, pp. 8041-8052, 2015.

[9] B. J. Anderson, "Thermal stability and lifetime estimates of a high temperature epoxy by $T_{\mathrm{g}}$ reduction," Polymer Degradation and Stability, vol. 98, no. 11, pp. 2375-2382, 2013.

[10] J. Wan, B. Gan, C. Li et al., “A novel biobased epoxy resin with high mechanical stiffness and low flammability: synthesis, characterization and properties," Journal of Materials Chemistry A, vol. 3, no. 43, pp. 21907-21921, 2015.

[11] H. Suryanto, E. Marsyahyo, Y. Surya Irawan, R. Soenoko, and Aminudin, "Improvement of interfacial shear strength of mendong fiber (Fimbristylis globulosa) reinforced epoxy composite using the AC electric fields," International Journal of Polymer Science, vol. 2015, 10 pages, 2015.

[12] A. Q. Barbosa, L. F. M. da Silva, J. Abenojar, M. Figueiredo, and A. Öchsner, "Toughness of a brittle epoxy resin reinforced with micro cork particles: effect of size, amount and surface treatment," Composites Part B: Engineering, vol. 114, pp. 299-310, 2017.

[13] M. Afendi, M. S. Abdul Majid, R. Daud, A. Abdul Rahman, and T. Teramoto, "Strength prediction and reliability of brittle epoxy adhesively bonded dissimilar joint," International Journal of Adhesion and Adhesives, vol. 45, pp. 21-31, 2013.

[14] S. Zavareh and G. Vahdat, "Toughening of brittle epoxy using bitumen as a new modifier," Journal of Reinforced Plastics and Composites, vol. 31, no. 4, pp. 247-258, 2012.

[15] R. Akbari, M. H. Beheshty, and M. Shervin, "Toughening of dicyandiamide-cured DGEBA-based epoxy resins by CTBN liquid rubber," Iranian Polymer Journal, vol. 22, no. 5, pp. 313-324, 2013.

[16] M. Hosseini, M. Esfandeh, M. Razavi-Nouri, and A. M. Rezadoust, "Effect of hybridization of carboxyl-terminated acrylonitrile butadiene liquid rubber and alumina nanoparticles on the fracture toughness of epoxy nanocomposites," Polymer Composites, vol. 40, no. 7, pp. 2700-2711, 2019.

[17] S. Liu, X. Fan, and C. He, "Improving the fracture toughness of epoxy with nanosilica-rubber core-shell nanoparticles," Composites Science and Technology, vol. 125, pp. 132-140, 2016.

[18] S. R. Mousavi and I. A. Amraei, "Toughening of dicyandiamide-cured DGEBA-based epoxy resin using MBS core-shell rubber particles," Journal of Composite Materials, vol. 49, no. 19, pp. 2357-2363, 2015. 
[19] Z.-P. Zou, X. B. Liu, Y. P. Wu, B. Tang, M. Chen, and X. L. Zhao, "Hyperbranched polyurethane as a highly efficient toughener in epoxy thermosets with reaction-induced microphase separation," RSC Advances, vol. 6, no. 22, pp. 1806018070, 2016.

[20] S. Chaudhary, P. Surekha, D. Kumar, C. Rajagopal, and P. K. Roy, "Amine-functionalized poly(styrene) microspheres as thermoplastic toughener for epoxy resin," Polymer Composites, vol. 36, no. 1, pp. 174-183, 2015.

[21] O. Moudam, T. Andrews, C. Lekakou, J. F. Watts, and G. Reed, "Carbon nanotube-epoxy nanocomposites: correlation and integration of dynamic impedance, dielectric, and mechanical analyses," Journal of Nanomaterials, vol. 2013, Article ID 801850, 11 pages, 2013.

[22] J.-L. Phua, P. L. Teh, S. A. Ghani, and C. K. Yeoh, "Effect of heat assisted bath sonication on the mechanical and thermal deformation behaviours of graphene nanoplatelets filled epoxy polymer composites," International Journal of Polymer Science, vol. 2016, Article ID 9767183, 8 pages, 2016.

[23] S. R. Mousavi and I. Amiri Amraei, "Influence of nanosilica and methyl methacrylate-butadiene-styrene core-shell rubber particles on the physical-mechanical properties and cure kinetics of diglycidyl ether of bisphenol-A-based epoxy resin," High Performance Polymers, vol. 28, no. 7, pp. 809-819, 2016.

[24] M. Ghaemy, S. M. A. Nasab, and M. Barghamadi, "Preparation and nonisothermal cure kinetics of DGEBA-nanosilica particles composites," Polymer Composites, vol. 29, no. 2, pp. 165172, 2008.

[25] F. I. Altuna, C. C. Riccardi, D. C. Marín Quintero, R. A. Ruseckaite, and P. M. Stefani, "Effect of an anhydride excess on the curing kinetics and dynamic mechanical properties of synthetic and biogenic epoxy resins," International Journal of Polymer Science, vol. 2019, Article ID 5029153, 8 pages, 2019.

[26] F. N. Tüzün, M. Gürü, and Y. Akyüz, "Comparison of the curing kinetic behavior for two epoxy resin systems containing EPIKOTE 828-EPIKURE 3090 and DURATEK KLM 606ADURATEK KLM 606B," Polymer Composites, vol. 28, no. 6, pp. 762-770, 2007.

[27] W. Ke, W. Rumin, and Z. Jinfang, "Curing kinetics of hybrid networks composed of benzoxazine and multifunctional novolac epoxy," International Journal of Polymer Science, vol. 2015, Article ID 629403, 8 pages, 2015.

[28] Y. Xu, Y. Yang, R. Shen et al., "Thermal behavior and kinetics study of carbon/epoxy resin composites," Polymer Composites, vol. 40, no. 12, pp. 4530-4546.

[29] F. Ferdosian, Y. Zhang, Z. Yuan, M. Anderson, and C. (. C.). $\mathrm{Xu}$, "Curing kinetics and mechanical properties of bio-based epoxy composites comprising lignin-based epoxy resins," European Polymer Journal, vol. 82, pp. 153-165, 2016.

[30] M. R. Saeb, M. Ghaffari, H. Rastin et al., "Biowaste chicken eggshell powder as a potential cure modifier for epoxy/anhydride systems: competitiveness with terpolymer-modified calcium carbonate at low loading levels," RSC Advances, vol. 7, no. 4, pp. 2218-2230, 2017.

[31] S. B. Jagtap and D. Ratna, "Effect of molecular weight of curing agents on properties of nanocomposites based on epoxy resin and organoclay with reactive modifier," Journal of Applied Polymer Science, vol. 134, no. 11, 2017.

[32] M. Hesabi, A. Salimi, and M. H. Beheshty, "Effect of tertiary amine accelerators with different substituents on curing kinetics and reactivity of epoxy/dicyandiamide system," Polymer Testing, vol. 59, pp. 344-354, 2017.
[33] G. R. Saad, A. A. Ezz, and H. A. Ahmed, "Cure kinetics, thermal stability, and dielectric properties of epoxy/barium ferrite/polyaniline composites," Thermochimica Acta, vol. 599, pp. 84-94, 2015.

[34] X. Xiong, X. Guo, R. Ren, L. Zhou, and P. Chen, “A novel multifunctional glycidylamine epoxy resin containing phthalide cardo structure: synthesis, curing kinetics and dynamic mechanical analysis," Polymer Testing, vol. 77, p. 105917, 2019.

[35] R. Ren, X. Xiong, X. Ma et al., "Isothermal curing kinetics and mechanism of DGEBA epoxy resin with phthalide- containing aromatic diamine," Thermochimica Acta, vol. 623, pp. 15-21, 2016.

[36] D.-d. Hu, J.-x. Lyu, T. Liu, M.-d. Lang, and L. Zhao, “Solvation effect of $\mathrm{CO}_{2}$ on accelerating the curing reaction process of epoxy resin," Chemical Engineering and Processing-Process Intensification, vol. 127, pp. 159-167, 2018.

[37] M. Nonahal, H. Rastin, M. R. Saeb et al., "Epoxy/PAMAM dendrimer-modified graphene oxide nanocomposite coatings: nonisothermal cure kinetics study," Progress in Organic Coatings, vol. 114, pp. 233-243, 2018.

[38] P. Poornima Vijayan, D. Puglia, H. Rastin, M. R. Saeb, B. Shojaei, and K. Formela, "Cure kinetics of epoxy/MWCNTs nanocomposites: isothermal calorimetric and rheological analyses," Progress in Organic Coatings, vol. 108, pp. 75-83, 2017.

[39] G. R. Saad, H. M. Abdallah, M. S. A. Aziz, N. A. Mohamed, and M. W. Sabaa, "Cure kinetics and thermal stability of maleimide modified epoxy TGIC/CPE powder coating system," Thermochimica Acta, vol. 617, pp. 191-199, 2015.

[40] O. de Andrade Raponi, R. de Andrade Raponi, G. B. Barban, R. M. Di Benedetto, and A. C. A. Junior, "Development of a simple dielectric analysis module for online cure monitoring of a commercial epoxy resin formulation," Materials Research, vol. 20, supplement 2, pp. 291-297, 2017.

[41] D. J. Hourston and J. M. Lane, "The toughening of epoxy resins with thermoplastics: 1. Trifunctional epoxy resinpolyetherimide blends," Polymer, vol. 33, no. 7, pp. 13791383, 1992.

[42] A. M. Rocco, C. P. Fonseca, F. A. M. Loureiro, and R. P. Pereiraa, "A polymeric solid electrolyte based on a poly(ethylene oxide)/poly(bisphenol A-co-epichlorohydrin) blend with $\mathrm{LiClO}_{4}$," Solid State Ionics, vol. 166, no. 1-2, pp. 115-126, 2004.

[43] Y. Kang, K. Cheong, K.-A. Noh, C. Lee, and D.-Y. Seung, “A study of cross-linked PEO gel polymer electrolytes using bisphenol A ethoxylate diacrylate: ionic conductivity and mechanical properties," Journal of Power Sources, vol. 119121, pp. 432-437, 2003.

[44] N. R. Paluvai, S. Mohanty, and S. K. Nayak, "Cure kinetics of exfoliated bio-based epoxy/clay nanocomposites developed from acrylated epoxidized castor oil and diglycidyl ether bisphenol A networks," High Performance Polymers, vol. 27, no. 8, pp. 918-929, 2015.

[45] A. K. Singh, B. P. Panda, S. Mohanty, S. K. Nayak, and M. K. Gupta, "Synergistic effect of hybrid graphene and boron nitride on the cure kinetics and thermal conductivity of epoxy adhesives," Polymers for Advanced Technologies, vol. 28, no. 12, pp. 1851-1864, 2017. 